\title{
A Meandered Line Patch Antenna at Low Frequency Range for Early Stage Breast Cancer Detection
}

\author{
Md Abdullah Al Rakib', Shamim Ahmad², Md. Humayun Kabir Khan³, Mainul Haque ${ }^{4}$, Tareq \\ Mohammad Faruqi ${ }^{5}$, Md Saroar Jahan ${ }^{6}$, Jhuma Kabir Mim ${ }^{7}$ \\ 1,3,4,5 Dept. of EEE, City University-Bangladesh, Dhaka 1216, Bangladesh \\ ${ }^{2}$ Dept. of EEE, American International University-Bangladesh, Dhaka, Bangladesh \\ ${ }^{6}$ Dept. of CMVS, University of Oulu, Finland \\ ${ }^{7}$ Dept. of Computational Engineering, LUT University, Finland \\ Email: \{alrakib108; ahmadshamim827; humayun10eee; mainul37; tareq.faruqi\}@gmail.com, mjahan18@edu.oulu.fi; \\ jhuma.mim@student.lut.fi
}

\begin{tabular}{l} 
Article Info \\
\hline Article history: \\
Received Oct 29, 2020 \\
Revised Jun 31, 2021 \\
Accepted Aug 19, 2021 \\
\hline Keywords: \\
Mendered Line Antenna \\
Breast Cancer \\
Microwave Imaging \\
SAR \\
Reflection Coefficient
\end{tabular}

Md Abdullah Al Rakib

Dept. of EEE, City University-Bangladesh, Dhaka, Bangladesh

alrakib108@gmail.com 
old, due to the denser breast tissue construction. Denser breast tissue may look white as the same as the tumor in the mammography report, which makes it harder to distinguish between healthy tissue and cancerous tissue [2].

Another effective method for tracing breast cancer is a biopsy. Although biopsy is a good method to track out the existence of breast cancer in women, there are still some issues to be considered. In the biopsy method, a needle is used to collect the tissue sample, which may not be sufficient, and therefore, this method may have to be repeated. Although samples are collected from the precise area, there is a chance of wrong results if the pathologist misdiagnoses the tissue as benign, but in reality, cancer may still present there. These types of issues can be avoided with surgical biopsy, but a surgical biopsy is a painful, time-consuming and costly procedure and misdiagnosis may occur if tissue samples are taken from the wrong area [3]. Other methods like ultrasound, tomography, and MRI have some side-effect due to harmful lionized radiation, especially when it comes to young women patients [4].

In recent days, the microwave imaging technique is receiving popularity because of its simple procedure and reasonable cost. In this system, a microwave signal is passed into the breast from an antenna, and in the existence of cancerous cells in the breast, the antenna receives a different back-scattered signal compering with the normal breast tissue [5]. This method does not require any intersection of skin that makes the process stress-free and painless for the patient. In addition, this method can also cover the whole area of the breast as well as any size. For the microwave imaging process, simple and compact types of antennas are required. For this reason, the patch antenna, also known as a printed antenna that fulfills the system's demand is often chosen.

There are several antennas were designed for breast cancer detection purposes, so far. For example, in reference [4], a conventional patch antenna was studied at $2.45 \mathrm{GHz}$ for breast cancer detection purposes. This paper only focused on the electrical field distribution of the antenna for detecting the existence of cancerous tissue inside the breast but the most important parameter SAR, which ensures patient safety, was absent in this paper. Also, the breast was not designed with maintaining an exact shape that might lead the results to inaccuracy. A circular shape patch antenna was created in reference [6]. This paper investigated the variations of the S-parameters to indicate the cancerous cells in the designed breast phantom. Although this paper considered patient safety by calculating SAR amount, the authors did not study the antenna performances by varying the tumor's positions. Parameters' data of a ring-shape patch antenna were examined by setting the antenna on a cubic shape breast phantom in [7]. The antenna operated within a wideband frequency range $(1.5 \mathrm{GHz}-7 \mathrm{GHz})$. This article also did not discuss anything about the antenna's SAR parameter, which makes the antenna questionable for the use of breast cancer detection. Five different shape microstrip patch antennas were studied in [1]. In addition, this paper designed an antenna array using the conventional microstrip patch antenna to check the credibility of their design for use in the microwave imaging system. A $16 \times 16$ flexible antenna at UWB frequency was designed in [8] the antenna's performances were checked over a cubic breast phantom which contents skin, fat, glandular tissue, and muscle but the authors did not explore the antenna performances, with a tumor inside the breast which incompletes the investigation of the antenna. An antenna array, using four antennas, was used to detect the cancerous cells in [9] at 1.5GHz. The S-parameter results of the antenna array showed a very uniform pattern for different positions of the tumor. Signal amplification variation versus time curve was studied in [10] for defected breast cell detection where the authors had used a UWB microstrip patch antenna. In addition, the bandwidth range of the antenna was $1.6 \mathrm{GHz}$ to $11.2 \mathrm{GHz}$. References [11] and [12] designed two miniaturized antennas at a lower frequency range for breast cancer detection, but none of them discussed the patient safety regulation for their antenna.

In this paper, a $14 \times 14$ compact antenna is assigned to localize the cancerous tumor inside the breast at a low-frequency range due to safety concerns as the antenna is about to operate in the on-body condition. A similarly structured breast to a real human having radius of $20 \mathrm{~mm}$ is designed for the sake of error-free results. In addition, tissue properties are considered accordingly as the microwave imaging process works based on tissue contrast in the aspects of electrical properties. The antenna was performed for two conditions, such as with tumor and without tumor, of the breast. Furthermore, the data are analyzed for various positions of the cancerous tumor. The paper is organized as follows: in section II, the designing methods of the antenna \& the breast phantom and the simulation set-up of the antenna are discussed. Section III describes the results of the antenna parameters for the breast without any tumor and with a tumor. Then in section IV, the antenna's performances with other reported works were compared. Lastly, in section V, the paper was concluded with a brief overview of this work.

\section{RESEARCH METHOD}

This part deals with the antenna and breast phantom designing. Also, with the simulation set-up for the parameter readings of the antenna. 


\subsection{Antenna Designing}

To design the meandered line microstrip patch antenna, which is shown in Figure 1, the worksheet of the CST MICROWAVE STUDIO SUITE 2020 is utilized. First of all, a $14 \times 14 \times 0.5$ square shape brick is created as a substrate where Rogger R030100 is employed as the material because of its flexible nature [13]. Then another brick of $12 \times 12 \times 1$ dimension is built as the antenna patch or radiator on one side of the substrate. Due to the amazing conductivity and electrical energy distribution ability, copper is chosen for the patch material as well as for the ground too [6]. Furthermore, the measurement of the ground is $14 \times 14 \times 1$, which is designed to be the opposite of the patch, on the substrate plate. Dimensions of the antenna plates can be visualized from Table 1 . The patch is cut accordingly to get the desired frequency at a low range.

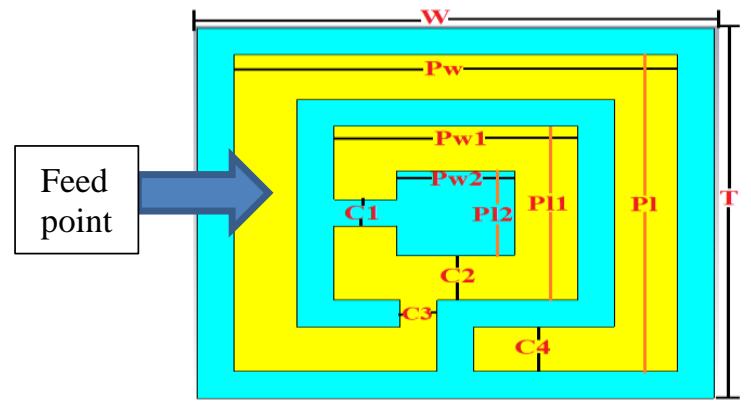

(a)

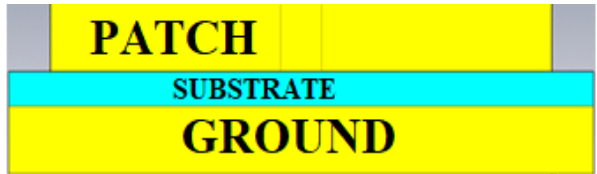

(b)

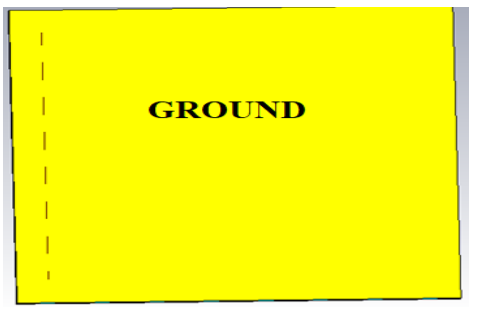

(c)

Figure 1. Antenna's view: (a) Frontal (b) Side (c) Back

Note that the operating frequency of the antenna can be changed by varying the length, width, and number of the patch slots. Used Materialistic properties' values of Copper and Roger R03010 are listed in Table 2.

Table 1. Details of the antenna plates

\begin{tabular}{lll}
\hline Layers & Material & Parameters in $\mathrm{mm}$ \\
\hline Patch & Copper & $\mathrm{Pw}=12, \quad \mathrm{Pl}=12, \quad \mathrm{Pw} 1=6.60, \quad \mathrm{Pl}=6.60$, \\
& & $\mathrm{Pw} 2=3.20, \mathrm{Pl}=3.20, \mathrm{C} 1=1, \mathrm{C} 2=1.70, \mathrm{C} 3=1$, \\
& $\mathrm{C} 4=1.70$ \\
Substrate & Rogger R01030 & $\mathrm{W}=14, \mathrm{~T}=14$ \\
Ground & Copper & $\mathrm{W}=14, \mathrm{~T}=14$ \\
\hline
\end{tabular}

Table 2. Detail physical property of Copper and Rogger R03010

\begin{tabular}{cl}
\hline Material & \multicolumn{1}{c}{ Property value with unit } \\
\hline Copper (Lossy metal) & Mu or dielectrical conductivity $=1$, electrical conductivity = \\
& $5.96 \mathrm{e}+07(\mathrm{~s} / \mathrm{m})$, Rho $=890\left(\mathrm{~kg} / \mathrm{m}^{2}\right)$, Thermal Conductivity $=401$ \\
& $(\mathrm{~W} / \mathrm{K} / \mathrm{m})$, Specific Heat $=390(\mathrm{~J} / \mathrm{K} / \mathrm{kg})$, Diffusivity $=0.00011541$ \\
& $\left(\mathrm{~m}^{2} / \mathrm{s}\right)$, Young's Module $=120\left(\mathrm{kN} / \mathrm{mm}^{2}\right)$, Poisson Ratio $=0.33$, \\
& Thermal Expansion $=17(1 \mathrm{e}-6 / \mathrm{k})$ \\
Rogger R03010 & Epsilon or permittivity $=10.2, \tan \delta$ or loss tangents $=0.0022$, \\
(Normal) & Thermal conductivity $=0.66(\mathrm{~W} / \mathrm{K} / \mathrm{m})$ \\
\hline
\end{tabular}

\subsection{Breast Phantom Designing}

To get accurate and closer to the practical value of results, it is important to design the breast as similar to the real human breast for simulation. Therefore, in this paper, a breast with actual shape and tissue construction is designed. The tissue properties of the breast are maintained properly during the creation. 
Created healthy breast mainly has four biological tissue layers, namely, skin, fat, gland or glandular tissue, and muscle [12] (Figure 2). The total radius and total height of the breast are $20 \mathrm{~mm}$ and $36 \mathrm{~mm}$, respectively. Detailed dimensions and properties of the used tissues for breast designing are mentioned in Table 3.

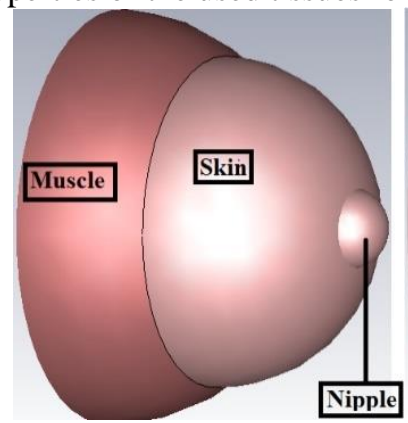

(a)

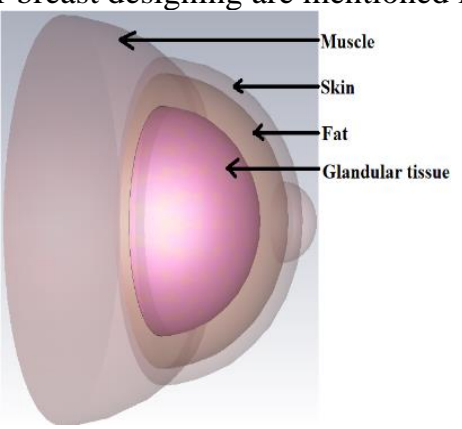

(b)

Figure 2. Designed healthy breast's view: (a) solid and (b) transparent

Table 3. Details of breast tissue

\begin{tabular}{|c|c|c|c|}
\hline Tissue & Outer radius $(\mathrm{mm})$ & Thickness (mm) & Property (unit) \\
\hline Skin & 20 & 2 & $\begin{array}{l}\text { Epsilon }=43.75, \mathrm{Mu}=1 \text {, Electrical } \\
\text { Conductivity }=0.856(\mathrm{~s} / \mathrm{m}), \text { Rho }=1100 \\
\left(\mathrm{~kg} / \mathrm{m}^{2}\right) \text {, Thermal Conductivity }=0.3 \\
(\mathrm{~W} / \mathrm{K} / \mathrm{m}), \text { Specific Heat }=3500(\mathrm{~J} / \mathrm{K} / \mathrm{kg}) \text {, } \\
\text { Diffusivity }=7.7921 \mathrm{e}-08\left(\mathrm{~m}^{2} / \mathrm{S}\right), \text { Blood } \\
\text { flow }=9000\left(\mathrm{~W} / \mathrm{K} / \mathrm{m}^{3}\right), \text { Metabolic Rate } \\
=2000\left(\mathrm{~W} / \mathrm{m}^{3}\right)\end{array}$ \\
\hline Fat & 18 & 4 & $\begin{array}{l}\text { Epsilon }=3, \mathrm{Mu}=1, \text { Electrical } \\
\text { Conductivity }=0.4(\mathrm{~s} / \mathrm{m}), \text { Rho }=910 \\
\left(\mathrm{~kg} / \mathrm{m}^{2}\right) \text {, Thermal Conductivity }=0.201 \\
(\mathrm{~W} / \mathrm{K} / \mathrm{m}) \text {, Specific Heat }=3500(\mathrm{~J} / \mathrm{K} / \mathrm{kg}) \text {, } \\
\text { Diffusivity }=\quad 8.8356 \mathrm{e}-08\left(\mathrm{~m}^{2} / \mathrm{S}\right) \text {, } \\
\text { Blood flow }=1700\left(\mathrm{~W} / \mathrm{K} / \mathrm{m}^{3}\right), \text { Metabolic } \\
\text { Rate }=300\left(\mathrm{~W} / \mathrm{m}^{3}\right)\end{array}$ \\
\hline Glandular & 14 & - & $\begin{array}{l}\text { Epsilon }=68.81, \mathrm{Mu}=1 \text {, Electrical } \\
\text { Conductivity }=0.794(\mathrm{~s} / \mathrm{m}), \text { Rho }=1040 \\
\left(\mathrm{~kg} / \mathrm{m}^{2}\right), \text { Thermal Conductivity }=0.6 \\
(\mathrm{~W} / \mathrm{K} / \mathrm{m}), \text { Specific Heat }=3600(\mathrm{~J} / \mathrm{K} / \mathrm{kg}) \text {, } \\
\text { Diffusivity }=1.6025 \mathrm{e}-07\left(\mathrm{~m}^{2} / \mathrm{S}\right), \text { Blood } \\
\text { flow }=400000\left(\mathrm{~W} / \mathrm{K} / \mathrm{m}^{3}\right), \text { Metabolic } \\
\text { Rate }=60000\left(\mathrm{~W} / \mathrm{m}^{3}\right)\end{array}$ \\
\hline Muscle & 25 & 7 & $\begin{array}{l}\text { Epsilon }=3, \mathrm{Mu}=1, \text { Electrical } \\
\text { Conductivity }=0.3(\mathrm{~s} / \mathrm{m}) \text {, Rho }=1041 \\
\left(\mathrm{~kg} / \mathrm{m}^{2}\right) \text {, Thermal Conductivity }=0.53 \\
(\mathrm{~W} / \mathrm{K} / \mathrm{m}), \text { Specific Heat }=(\mathrm{J} / \mathrm{K} / \mathrm{kg}) \text {, } \\
\text { Diffusivity }=\left(\mathrm{m}^{2} / \mathrm{S}\right), \text { Blood flow }= \\
\left(\mathrm{W} / \mathrm{K} / \mathrm{m}^{3}\right), \text { Metabolic Rate }=\left(\mathrm{W} / \mathrm{m}^{3}\right)\end{array}$ \\
\hline
\end{tabular}

\subsection{Simulation Set-up}

At first, the antenna was designed and investigated in free space, the resonance frequency of the antenna at free space was found at $2.452 \mathrm{GHz}$. But as the antenna is about to use for breast cancer detection so the antenna is set over the designed healthy breast (Figure 3 (a)) as well as over the affected breast (Figure 3 (b)) as up-side-down. For affected breast designing, a tumor (dielectric conductivity $=4$ and relative permittivity $=50$ [4]), with a $5 \mathrm{~mm}$ radius is fitted inside the breast's glandular tissue. The antenna is investigated for six different positions such as No-tumor, Middle, Down-side, Up-side, Right-side, and Leftside of the cancerous cells inside the breast as is shown in Figure 4. The co-ordinates of the tumor are recoded as $(0,0,-20)$ for Middle, $(0,-10,-20)$ for Down-side, $(0,9,-20)$ for Up-side, $(10,0,-20)$ for Right-side and $(-10,0$,20) for Left-side. 


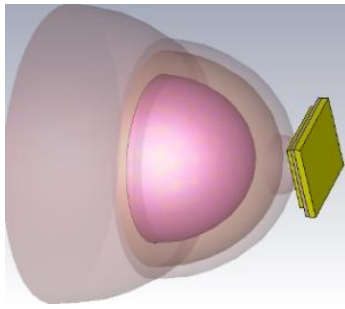

(a)

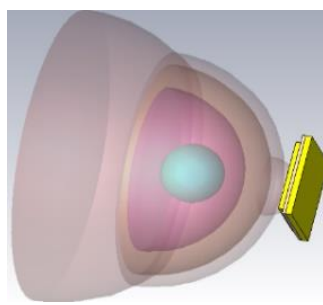

(b)

Figure 3. The antenna is set up as up-side-down over: (a) the healthy breast phantom and (b) the affected breast phantom with a tumor inside gland tissue

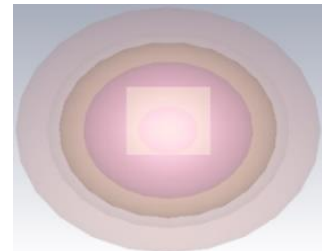

(a)

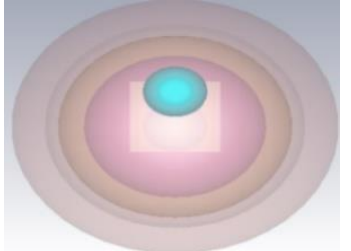

(d)

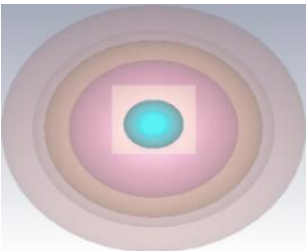

(b)

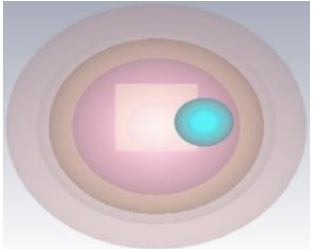

(e)

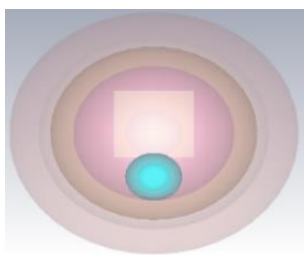

(c)

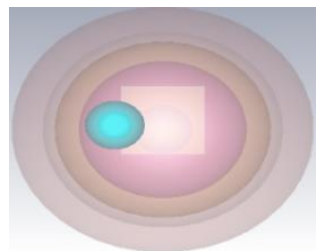

(f)

Figure 4. Tumor positions inside the braest: (a) No tumor, (b) Middle, (c) Down-side, (d) Up-side (e) Rightside and (f) Left-side

\section{RESULTS ANALYSIS}

This section deals with the antenna's obtained results for the simulation environment as shown in Figure 4.

\subsection{S-parameter or Reflection Coefficient}

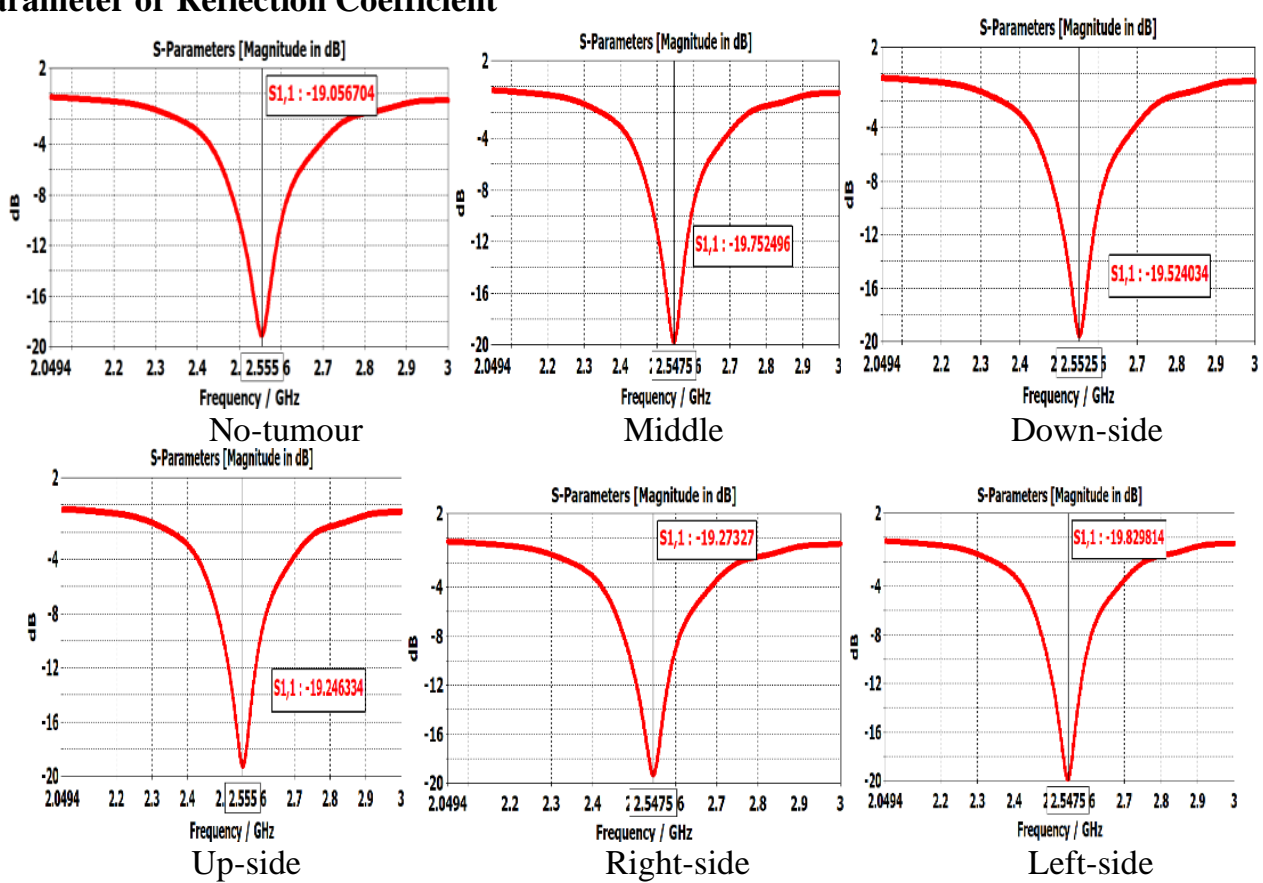

Figure 5. Antenna's S11 or Return loss values for different positions of the tumor inside the breast 
Return loss also familiar as S-parameter mainly denotes the amount of power reflected from the antenna [14]. In this study, S-parameter is used to distinguish between cancer-affected breast and healthy breast. In the absence of cancerous cells inside the breast phantom, The S11 or S-parameter is found -19.057 at $2.555 \mathrm{GHz}$, wherein the existence of the tumor at any position in the breast the antenna provides lower values of S-parameter that can be observed from Figure 5. Also, Table 4 clearly explains the S11 values and tuning frequencies for different positions of the tumor. In addition, the table shows that the antenna has the same resonance frequency for no-tumor and up-side condition of the tumor but the S-parameter values are not equal. Therefore, S-parameter can be utilized as a tumor and non-tumor indicator for this design.

Table 4. Variations of S-parameter values and frequency for different positions of the tumor

\begin{tabular}{ccc}
\hline Tumor position & S11 $(\mathrm{dB})$ & Frequency $(\mathrm{GHz})$ \\
\hline No tumor & -19.057 & 2.555 \\
Middle & -19.753 & 2.548 \\
Down-side & -19.524 & 2.553 \\
Up-side & -19.246 & 2.555 \\
Right-side & -19.273 & 2.548 \\
Left-side & -19.83 & 2.548 \\
\hline
\end{tabular}

\subsection{Voltage Standing Wave Ratio (VSWR)}

Voltage Standing Wave Ratio or VSWR parameter represents the antenna matching-capability with the system. An antenna VSWR value needs to be less than 2 and VSWR value 1 is considered as ideal VSWR value [15]. From Figure 6, it is clear that the antenna is well matched with the system, as for all of the statuses such as with tumor and without tumor of the breast the antenna's VSWR values are less than 2 . VSWR values are 1.251, 1.230, 1.236, 1.245, 1.25 and 1.227 for No-tumor, Middle, Down-side, Up-side, Right-side and Leftside position, respectively.
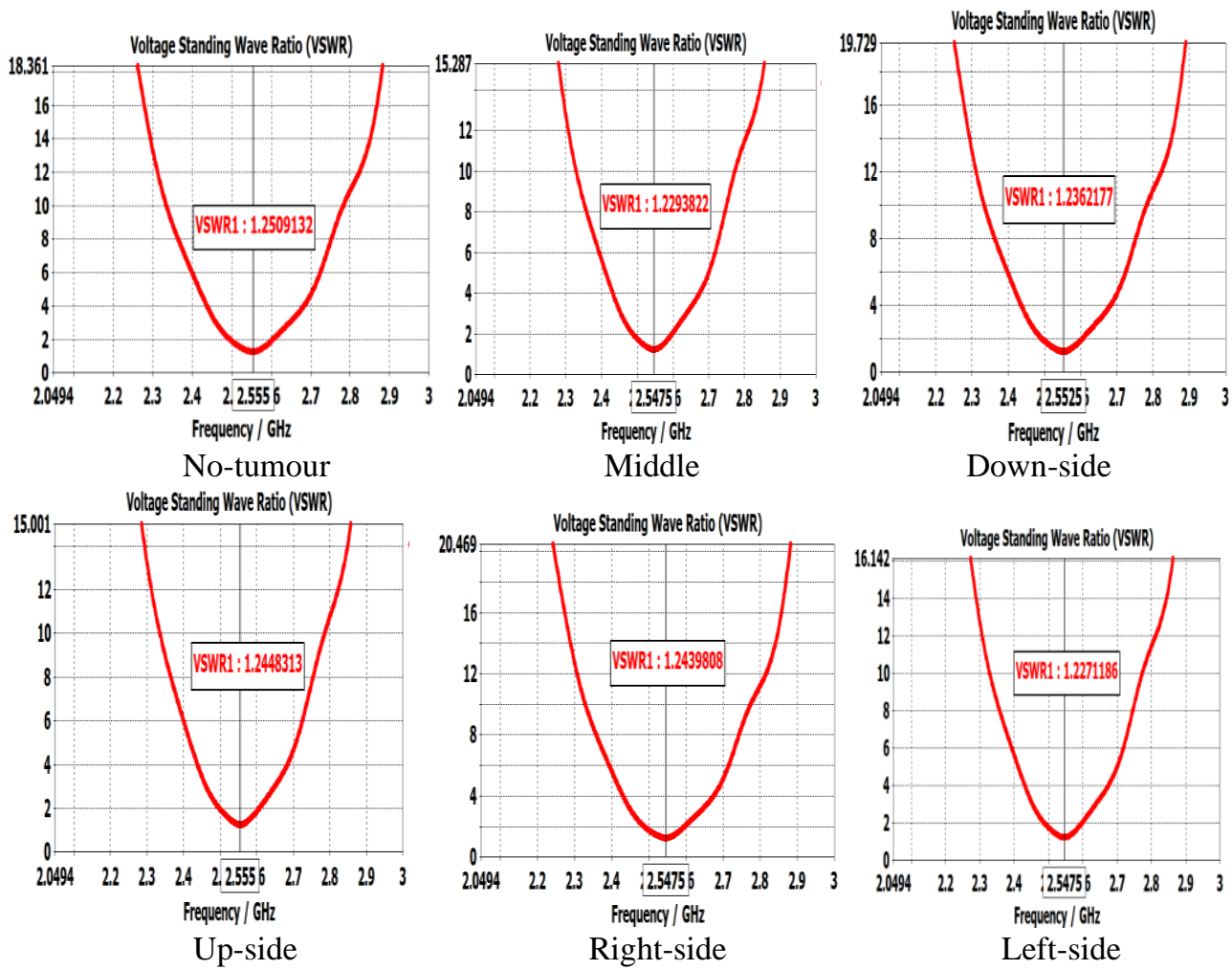

Figure 6. VSWR values of the antenna for different statuses of the breast

\subsection{Analysis of Electrical Properties to Locate the Positions of the Tumour}

The antenna's electrical field intensity (Figure 7) and current density (Figure 8) are scrutinized for all of the positions of the tumor at their particular frequency in search of the location of the defected cells. Table 5 makes a clear understanding of the electrical field intensity and current density of the antenna for the variations of the tumor's position. From Table 5, it can be seen that the current density and electric field intensity of the antenna are higher for the Middle, Right-side, and Left-side positions of the tumor than in 
normal conditions (No-tumour). However, these values are lower than normal conditions while the breast contains a tumor at Down-side and Up-side.

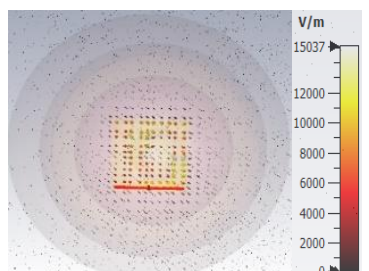

No-tumour $(2.555 \mathrm{GHz})$

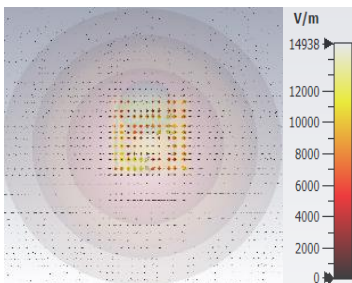

Up-side $(2.555 \mathrm{GHz})$

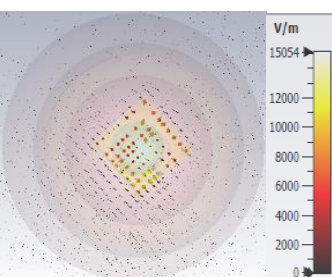

Middle $(2.5475 \mathrm{GHz})$

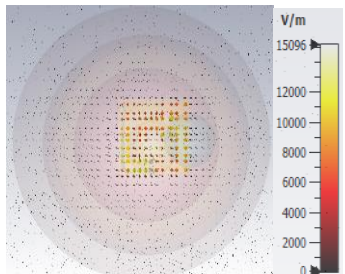

Right-side $(2.5475 \mathrm{GHz}) \quad$ Left-side $(2.5475 \mathrm{GHz})$

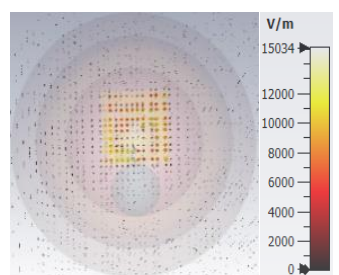

Down-side $(2.5525 \mathrm{GHz})$

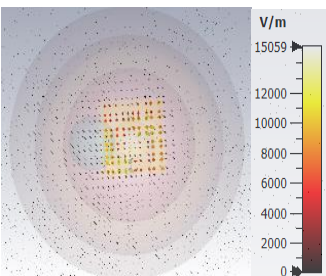

Figure 7. Electrical Field Intensity of the antenna for diverse conditions of the breast at a different frequency

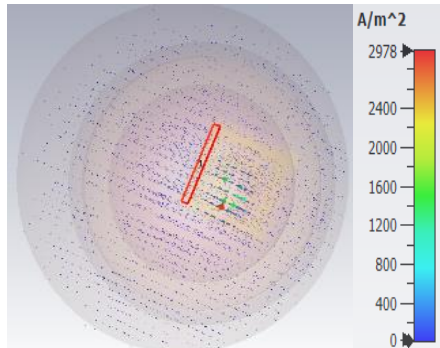

No-tumour $(2.555 \mathrm{GHz})$

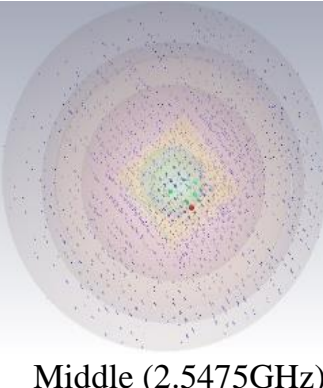

Middle $(2.5475 \mathrm{GHz})$

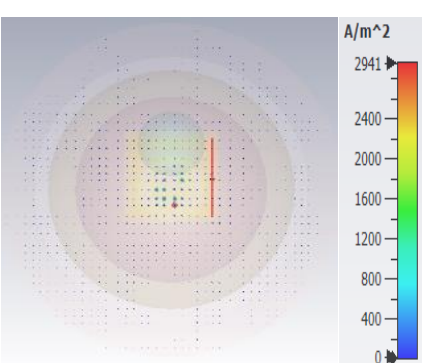

Up-side $(2.555 \mathrm{GHz})$

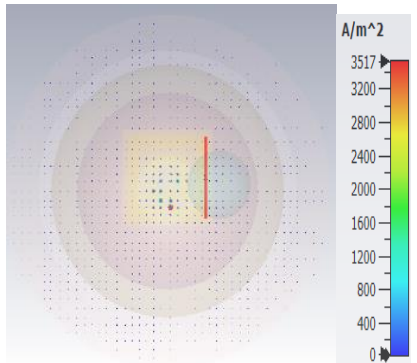

Right-side $(2.5475 \mathrm{GHz})$

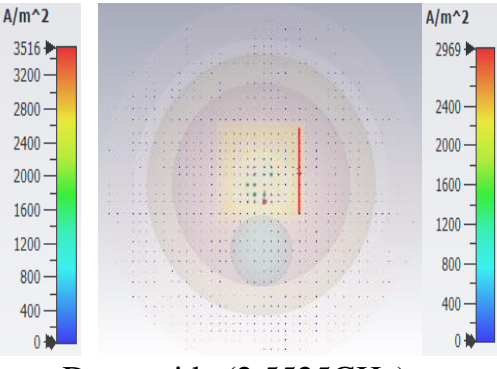

Down-side $(2.5525 \mathrm{GHz})$

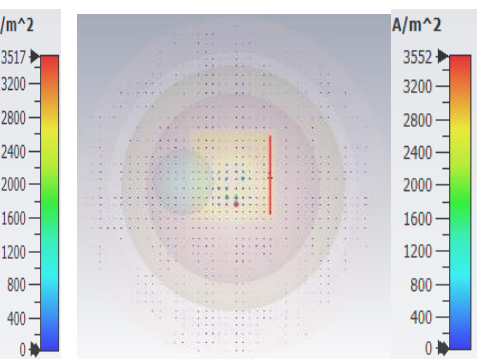

Left-side $(2.5475 \mathrm{GHz})$

Figure 8. Current Density of the Antenna for different situations of tumor

Table 5. Summary of antenna's E-field intensity and current density with frequency for various positioning of the tumor

\begin{tabular}{cccc}
\hline $\begin{array}{c}\text { Tumour } \\
\text { position }\end{array}$ & $\begin{array}{c}\text { E-field } \\
\text { Intensity }(\mathrm{V} / \mathrm{m})\end{array}$ & $\begin{array}{c}\text { Current Density } \\
\left(\mathrm{A} / \mathrm{m}^{2}\right)\end{array}$ & Frequency $(\mathrm{GHz})$ \\
\hline No-tumour & 15037 & 2978 & 2.555 \\
Middle & 15054 & 3516 & 2.5475 \\
Down-side & 15034 & 2969 & 2.5525 \\
UP-side & 14038 & 2941 & 2.555 \\
Right-side & 15096 & 3517 & 2.5475 \\
Left-side & 15059 & 3552 & 2.5475 \\
\hline
\end{tabular}


In Table 6, an estimation chart is stated for a better understanding of the tumor's area. If the achieved electrical properties match with the normal condition of the electrical properties, that means the breast is cancer-free, but if the obtained value does not match then, cancerous cells are present.

Table 6. Estimated tumor's area depending on antenna's electrical property

\begin{tabular}{lc}
\hline \multicolumn{1}{c}{ Status } & Tumour area \\
\hline Achieved Electrical Property $=$ Standard & No tumor \\
Condition Electrical Property & \\
Achieved Electrical Property $>$ Standard & Middle, Right-side, Left-side \\
Condition Electrical Property & \\
Achieved Electrical Property $<$ Standard & Down-side, Up-side \\
Condition Electrical Property & \\
\hline
\end{tabular}

\subsection{Radiation Pattern Analysis}

Antenna's radiation patterns are presented in Figure 9 and Figure 10 as 3-D and 1-D view, respectively. Theoretically, an antenna directivity can be $0 \mathrm{dBi}$, when the antenna has equal radiation to all of the directions [16]. Figure 9 depicts that the antenna directivity values are between $2.89 \mathrm{dBi}$ to $2.79 \mathrm{dBi}$ for any of the conditions of the breast, such as affected and unaffected, which means the antenna can cover the breast from any direction. At $2.555 \mathrm{GHz}$, the highest radiation efficiency is $-21.72 \mathrm{~dB}$, and the highest total efficiency is $27.27 \mathrm{~dB}$, of the antenna are observed when the tumor locates at Down-side in the breast, and the lowest values are $-27.50 \mathrm{~dB}$ for radiation efficiency and $-27.09 \mathrm{~dB}$ for total efficiency at $2.548 \mathrm{GHz}$, which is recorded when the tumor's position is at the Right-side in the breast.
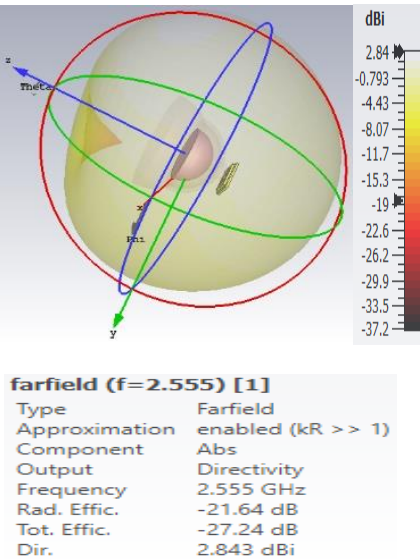

No-tumour
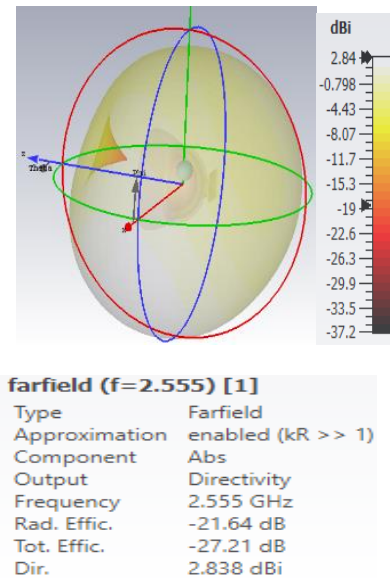

Up-side

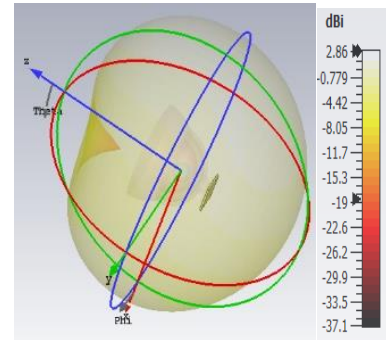

farfield $(f=2.5475)[1]$

Type

Approximation enabled (kR >> 1 )

Compone

Frequenc

Rad. Effic.

Tot. Eff.

Middle
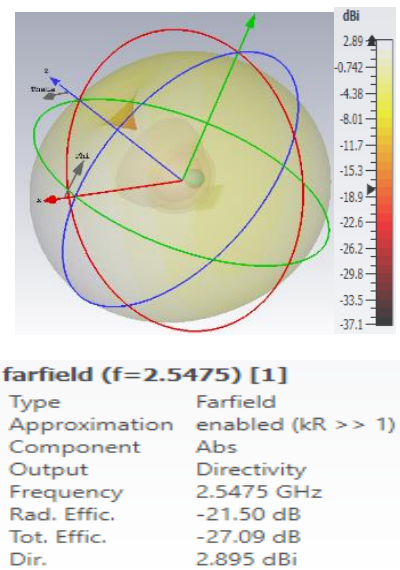

Right-side

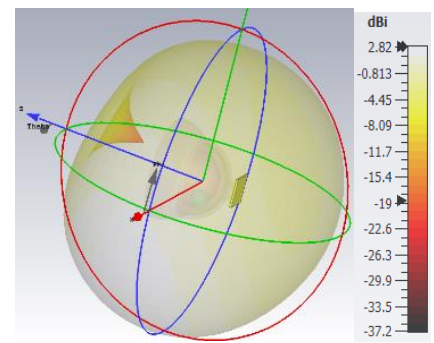

farfield $(f=2.5525)[1]$

Type Farfield

Approximation enabled (kR >> 1) Component

Output

Frequency

Rad. Effic.

Tot.

Abs

Directivity

$2.5525 \mathrm{GH}$

$-21.72 \mathrm{~dB}$

$2.824 \mathrm{dBi}$

Down-side

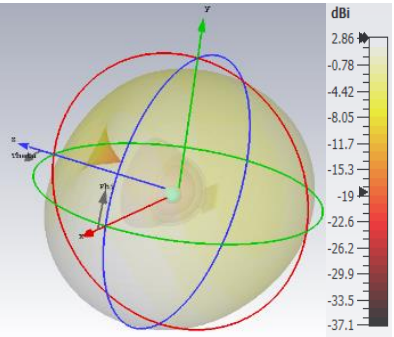

farfield $(f=2.5475)$ [1]

Type Farfield

Approximation enabled ( $k R>>1)$

Component Abs

Output Directivity

Frequency $\quad 2.5475 \mathrm{GHz}$

Rad. Effic. $\quad-21.61 \mathrm{~dB}$

Tot. Effic. $\quad-27.15 \mathrm{~dB}$

Dir.

$2.856 \mathrm{dBi}$

Left-side

FIG. 9. 3-D Radiation Patterns of the antenna for different positions of the tumor inside the breast

Antenna's radiation patterns in the polar form are represented in Figure 10, which explains the antenna radiation in terms of degree. The main lobe magnitude, which is $2.23 \mathrm{dBi}$ at $2.5475 \mathrm{GHz}$, of the antenna is maximum when it operates over the breast with a tumor at Right-side in it and minimum, which is $2.16 \mathrm{dBi}$ at $2.555 \mathrm{GHz}$ and $2.5525 \mathrm{GHz}$, for both No-tumour and down-side conditions of the tumor. The parameters of the

Antenna at Low Frequency Range for Early Stage Breast Cancer Detection (Md Abdullah Al Rakib et al) 
3-D and 2-D far-field radiation patterns for different positions of the tumor at their respective center frequency are codified in Table7.

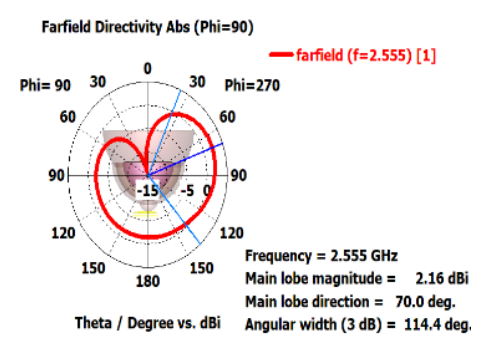

No-tumour

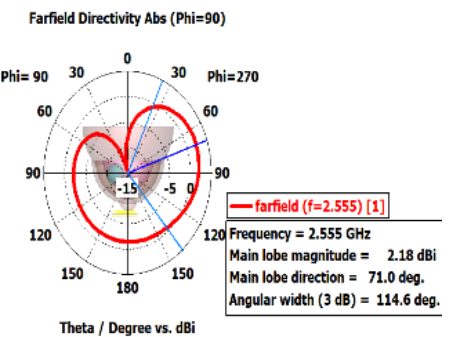

Up-side

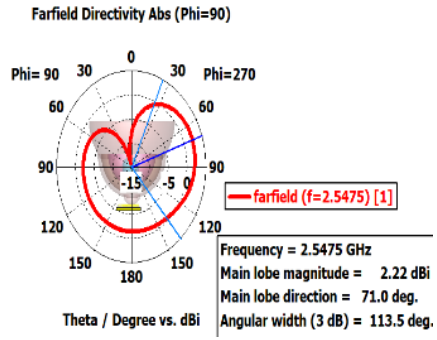

Middle

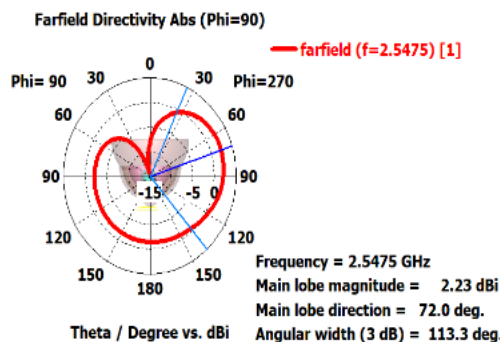

Right-side

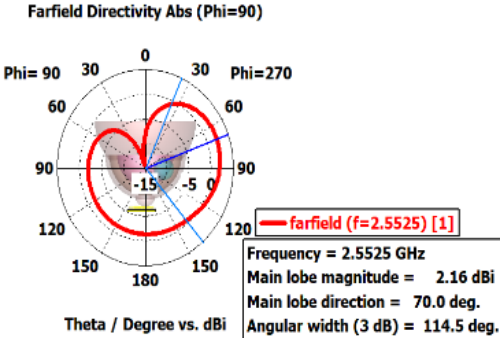

Down-side
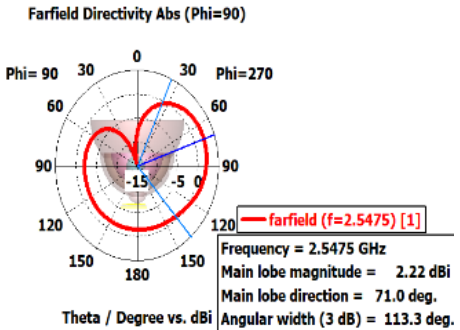

Left-side

Figure 10. 1-D (Polar view) Radiation Patterns of the antenna for different positions of the tumor inside the breast

Table 7. Parameters' summary of the antenna's 3-D and 2-D Fairfield view

\begin{tabular}{|c|c|c|c|c|c|c|c|}
\hline $\begin{array}{l}\text { Tumour } \\
\text { position }\end{array}$ & $\begin{array}{c}\text { Frequency } \\
\qquad(\mathrm{GHz})\end{array}$ & $\begin{array}{l}\text { Directivity } \\
\text { (dBi) }\end{array}$ & $\begin{array}{c}\text { Radiation } \\
\text { Efficicency } \\
\text { (dB) }\end{array}$ & $\begin{array}{c}\text { Total } \\
\text { Efficiency } \\
\text { (dB) }\end{array}$ & $\begin{array}{l}\text { Main lobe } \\
\text { magnitude } \\
\quad(\mathrm{dBi})\end{array}$ & $\begin{array}{l}\text { Main lobe } \\
\text { direction } \\
\text { (Degree) }\end{array}$ & $\begin{array}{l}\text { Angular } \\
\text { width } \\
\text { (Degree) }\end{array}$ \\
\hline Middle & 2.5475 & 2.86 & -21.60 & -27.14 & 2.22 & 71.0 & 113.4 \\
\hline Right-side & 2.5475 & 2.89 & -21.50 & -27.09 & 2.23 & 72.0 & 113.3 \\
\hline Left-side & 2.5475 & 2.86 & 21.61 & -27.09 & 2.22 & 71.0 & 113.3 \\
\hline
\end{tabular}

\subsection{Specific Absorption Rate (SAR)}

Specific Absorption Rate, in brief SAR, is the essential parameter to consider as it is an exhibitor of patient safety. It mainly indicates the amount of antenna's radiated electromagnetic energy that is absorbed by the near side body tissue [15]. The antenna's SAR values for the breast with diverse positioned tumors are calculated at their center frequencies due to patient safety purposes. The SAR values are measured for 10 grams of body tissue while the antenna input power is fixed at one milli-watt. All the obtained values of SAR are found within the maximum tolerable range $(2 \mathrm{~W} / \mathrm{kg})$, which is set by the International electro-technical Commission (IEC) [14], which can be checked from Figure 11. Maximal SAR value (1.27 W/kg at 2.5475GHz) is encountered for the Right-side positioning of the tumor in the breast. SAR values and frequencies concerning tumor positions are given in Table 8 . 

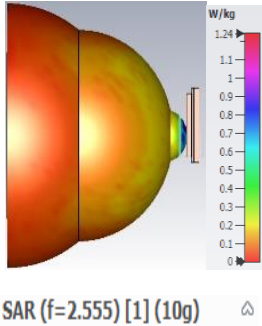

Frequency $\quad 2.555 \mathrm{GHz}$

Maximum (Solver) 1.24137 W/kg

Minimum (Solver) OW/kg

No-tumour

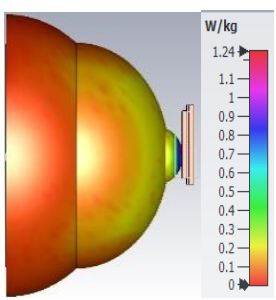

$\operatorname{SAR}(\mathrm{f}=2.555)[1](10 \mathrm{~g})$

Frequency $\quad 2.555 \mathrm{GHz}$

Maximum (Solver) $1.24212 \mathrm{~W} / \mathrm{kg}$

Minimum (Solver) OW/kg

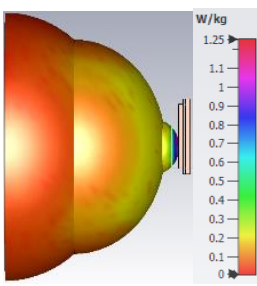

$\operatorname{SAR}(f=2.5475)[1](10 \mathrm{~g})$

Frequency $\quad 2.5475 \mathrm{GHz}$

Maximum (Solver) 1.24976 W/kg

Minimum (Solver) OW/kg

Middle

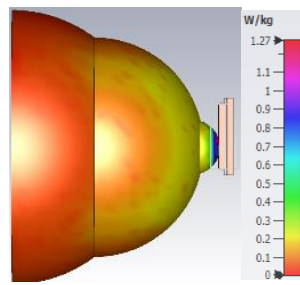

$\operatorname{SAR}(\mathrm{f}=2.5475)[1](10 \mathrm{~g})$

Frequency $\quad 2.5475 \mathrm{GHz}$

Maximum (Solver) $1.26889 \mathrm{~W} / \mathrm{kg}$

Minimum (Solver) $0 \mathrm{~W} / \mathrm{kg}$

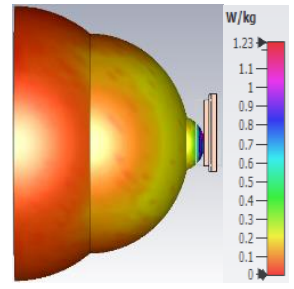

$\operatorname{SAR}(f=2.5525)[1](10 \mathrm{~g})$

Frequency $\quad 2.5525 \mathrm{GHz}$

Maximum (Solver) $1.23592 \mathrm{~W} / \mathrm{kg}$

Minimum (Solver) 0 W/kg

Down-side

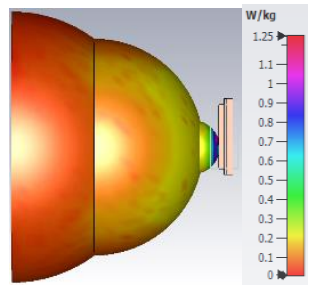

$\operatorname{SAR}(f=2.5475)[1](10 \mathrm{~g}) \quad \omega$

Frequency $\quad 2.5475 \mathrm{GHz}$

Maximum (Solver) $1.24681 \mathrm{~W} / \mathrm{kg}$

Minimum (Solver) $0 \mathrm{~W} / \mathrm{kg}$

Left-side

Figure 11. Simulated SAR values of the antenna at different states of the tumor in the breast

Table 8. Antenna's SAR values with respect to tumour positions

\begin{tabular}{ccc}
\hline Tumour's region & SAR value $(\mathrm{W} / \mathrm{kg})$ & Frequency $(\mathrm{GHz})$ \\
\hline No-tumour & 1.24 & 2.555 \\
Middle & 1.25 & 2.5475 \\
Down-side & 1.23 & 2.5525 \\
Up-side & 1.24 & 2.555 \\
Right-side & 1.27 & 2.5475 \\
Left-side & 1.25 & 2.5475 \\
\hline
\end{tabular}

\subsection{Comparison Analysis with Similar Published Works}

This antenna is one of the compact antennas comparing with previously reported works, which is illustrated in Table 9. Although researchers from [6] and [9] investigated patient's safety regarding contact with the antenna, others did not, which makes those designs impractical to use in the real system. Ref. [18] evaluated its antenna in free space and claimed that the antenna can detect cancer. Also, all of the papers (without Ref. [9]) presented data for only one position of the tumor. On the other hand, we consider five different positions of the tumor for presenting the data. Moreover, this paper considers patient safety from harmful electromagnetic radiation energy by measuring SAR-parameter and found the values within the accepted range according to IEC. Furthermore, this paper uses the most realistic simulation environment, comparing with other mentioned references in Table 9, for errorless and precise results as it is proven by Ref. [6] that shape may affect the results. Though Ref. [6] and [1] designed their breast maintaining actual shape, they did not consider the nipple part, and reference [17] created a hollow breast. So, considering the simulation set-up, antenna's whole volume, and safety measurement, from Table 9, this antenna will be more suitable than other works for breast cancer detection in the practical field. 
Table 9. Comparison of this work with other similar works

\begin{tabular}{|c|c|c|c|}
\hline Ref. & Breast shape & $\begin{array}{l}\text { Antenna Volume } \\
\left(\mathrm{mm}^{3}\right)\end{array}$ & $\begin{array}{l}\text { Tissue Safety } \\
\text { Consideration }\end{array}$ \\
\hline [4] & $\begin{array}{l}\text { Cubic shape } \\
\text { phantom }\end{array}$ & 9244.36 & No \\
\hline [6] & $\begin{array}{l}\text { Actual shape } \\
\text { Phantom }\end{array}$ & 3497.94 & Yes \\
\hline [7] & $\begin{array}{l}\text { Cubic shape } \\
\text { phantom }\end{array}$ & 3393.84 & No \\
\hline [1] & $\begin{array}{l}\text { Actual shape } \\
\text { phantom }\end{array}$ & 9253.72 & No \\
\hline [8] & $\begin{array}{l}\text { Cubic shape } \\
\text { phantom }\end{array}$ & 512 & No \\
\hline [9] & $\begin{array}{l}\text { Cubic shape } \\
\text { phantom }\end{array}$ & 1545.48 & Yes \\
\hline [17] & $\begin{array}{l}\text { Hollow actual } \\
\text { shape phantom }\end{array}$ & 2862 & No \\
\hline [11] & $\begin{array}{l}\text { Pyramid shape } \\
\text { phantom }\end{array}$ & 400 & No \\
\hline [18] & $\begin{array}{l}\text { No breast is } \\
\text { designed }\end{array}$ & 763.14 & No \\
\hline $\begin{array}{l}\text { This } \\
\text { paper }\end{array}$ & $\begin{array}{l}\text { Actual shape } \\
\text { phantom }\end{array}$ & 401.8 & Yes \\
\hline
\end{tabular}

\section{CONCLUSION}

In this article, a tiny-shape meandered line microstrip patch antenna is presented at a low-frequency range for breast cancer detection. For examining the antenna performances and parameters' result, the antenna has set over a cancer-free breast as well as the cancer-affected breast with maintaining their all-important properties. Good outcomes have been found for simulation results such as return loss, VSWR, radiation pattern, current density, electrical field intensity, and SAR calculation for both states of the breast (affected and healthy). For cancer detection, S-parameter or return loss values mainly help as an indicator as they are reduced by a considerable value in the presence of a tumor. Besides, fluctuations of the antenna's electrical properties' values, which mainly happened due to the variations of the tumor's position, assist in tracing the location of the tumor. Lastly, SAR reveals patient safety in contact with the antenna. So, keeping in mind the antenna performances, it would be fruitful to use this antenna to detect breast cancer in practical life.

\section{REFERENCES}

[1] K. Ouerghi, N. Fadlallah, A. Smida, R. Ghayoula, J. Fattahi and N. Boulejfen. Circular antenna array design for breast cancer detection. 2017 Sensors Networks Smart and Emerging Technologies (SENSET). Beirut. 2017: 1-4.

[2] Magnus Løberg, Mette Lise Lousdal, Michael Bretthauer, M. Kalager. Benefits and harms of mammography screening. Breast Cancer Research. 2015. Vol. 17 article no. 63 (2015): 1-12

[3] Errani, F. Traina, F. Perna, C. Calamelli, C. Faldini. Currentconcepts in the biopsy of musculoskeletal tumors. Sci. World J.. 2013 vol. 2013, 2013, Art. no. 538152.

[4] R. Çalışkan, S. S. Gültekin, D. Uzer, Ö. Dündar. A Microstrip Patch Antenna Design for Breast Cancer Detection. Procedia - Social and Behavioral Sciences. 2015; 195: 2905-2911.

[5] H. Zhang, T. Arslan, B. Flynn. A single antenna based microwave system for breast cancer detection: Experimental results. 2013 Loughborough Antennas \& Propagation Conference (LAPC). Loughborough. 2013: 477-481.

[6] A. Aziz, D. Ahmad, T. A. Shila, S. Rana, R. R. Hasan, M. A. Rahman. On-Body Circular Patch Antenna for Breast Cancer Detection. 2019 IEEE International Electromagnetics and Antenna Conference (IEMANTENNA), Vancouver. 2019: 29-34.

[7] F. Mansoor, T. Tan, S. I. Latif. The performance of an Ultra-wideband elliptical ring monopole antenna with a humanoid breast phantom. IEEE International Symposium on Antennas and Propagation \& USNC/URSI National Radio Science Meeting. San Diego. 2017: 105-106.

[8] P. K. Rao, R. Mishra, "Ultra-wide-band Flexible Antenna for Breast Cancer Detection. IEEE 5th International Conference for Convergence in Technology (I2CT). Bombay. 2019: 1-4. 
[9] M. M. U. Rashid, A. Rahman, L. C. Paul, J. Rafa, B. Podder, A. K. Sarkar. Breast Cancer Detection \& Tumour Localization Using Four Flexible Microstrip Patch Antennas. International Conference on Computer, Communication, Chemical, Materials and Electronic Engineering (IC4ME2). Rajshahi. 2019: 1-6.

[10] F. Alsharif, C. Kurnaz. Wearable Microstrip Patch Ultra Wide Band Antenna for Breast Cancer Detection. 201841 st International Conference on Telecommunications and Signal Processing (TSP), Athens. 2018: 1-5.

[11] R. Karli, H. Ammor, R. M. Shubair, M. I. AlHajri, R. Alkurd, A. Hakam. Miniature planar ultra-wide-band microstrip antenna for breast cancer detection. 2016 16th Mediterranean Microwave Symposium (MMS), Abu Dhabi, 2016: 14.

[12] Z. Katbay, S. Sadek, R. Lababidi, A. Perennec, M. le Roy. Miniature antenna for breast tumour detection. 2015 IEEE 13th International New Circuits and Systems Conference (NEWCAS). Grenoble. 2015: 1-4.

[13] S. Ahmad, R. R. Hasan, R. Hasan, M. A. Al Rakib, M. A. Hasan, M. Zubayar. A Low SAR In-Body Antenna for Wireless Monitoring Purpose of Pacemaker System. 4th International Conference on Electrical Information and Communication Technology (EICT). Khulna. 2019: 1-6.

[14] S. Ahmad, M. R. Islam, M. A. Haque, K. A. Mazed, R. R. Hasan, M. Fahim-Uz-Zaman. Body Implantable Patch Antenna for Biotelemetry System. 2018 International Electrical Engineering Congress (iEECON). Krabi. 2018: 1-4.

[15] S. Ahmad, R. Hasan, S. Das, M. H. Rabbi. Design and Performance Measurement of an On-body Capacitively Loaded Planar Inverted-F Antenna for Bio-medical Applications. International Conference on Innovations in Science, Engineering and Technology (ICISET). Chittagong. 2018: 222-225.

[16] T. A. Aleef, Y. B. Hagos, V. H. Minh, S. Khawaldeh, U. Pervaiz. Design and simulation-based performance evaluation of a miniaturised implantable antenna for biomedical applications. Micro \& Nano Lettter. 2017; 12(10): 821-826.

[17] I. Amdaouch, O. Aghzout, A. V. Alejos. Confocal microwave imaging algorithm for breast cancer detection based on a high directive corrugated vivaldi antenna pulses. International Conference on Wireless Technologies, Embedded and Intelligent Systems (WITS). Fez. 2019: 1-5.

[18] N. Hammouch, H. Ammor. Smart UWB antenna for early breast cancer detection. ARPN Journal of Engineering and Applied Sciences. 2018; 13(11): 3803-3808.

\section{BIOGRAPHIES OF AUTHORS}

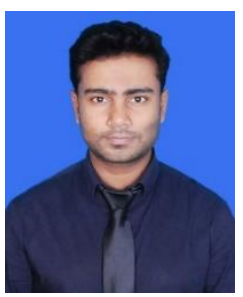

Md Abdullah Al Rakib received Bachelor of Science (B.Sc.) in EEE from American International University-Bangladesh (AIUB). He started his career in September 2018 at City UniversityBangladesh (CUB) as Lecturer in the Dept. of EEE. His research interest is focused on Power, electronics, IoT, and Telecommunication.

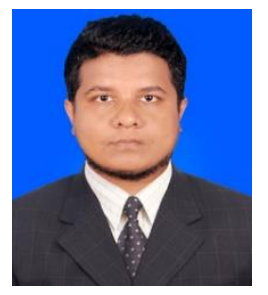

Shamim Ahmad was born in Narsingdi, Bangladesh in 1994. He received the B.Sc. degree in Electrical and Electronic Engineering from American International University-Bangladesh (AIUB), Dhaka, Bangladesh, in 2018. He has published several articles in international journals and conferences as an author or co-author. Currently, he is working as an independent researcher on bio-medical antenna designing and their improvements and preparing himself for higher study. His current research interests include bio-medical antenna designing \& testing and RF- triggered medical devices.

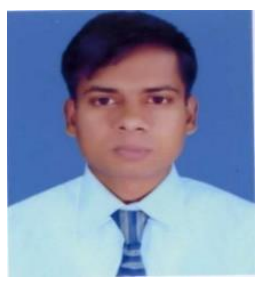

Md. Humayun Kabir Khan received a Bachelor's and Master's degree in EEE from Dhaka University of Engineering \& Technology (DUET). He started his career in April 2014 at City University, Bangladesh as a Senior Lecturer in the Dept. of EEE. Currently, he has been working as an Assistant Professor in the same Department and University. His research interests are focused on Power Electronics, Telecommunication, and Embedded Systems.

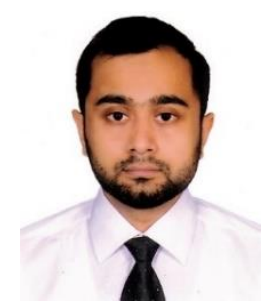

Mainul Haque received MSc in Electrical Engineering from the Frederick University, Cyprus in 2018, his BSc in Electrical \& Electronic Engineering from the United International University, Bangladesh in 2013. He is currently working as a Lecturer in the Department of Electrical \& Electronic Engineering, City University-Bangladesh (CUB). He has more than 5 years of experience in teaching and research. His research interests are Artificial Intelligence, VLSI, Embedded Systems, Nanotechnology, and Optics. 


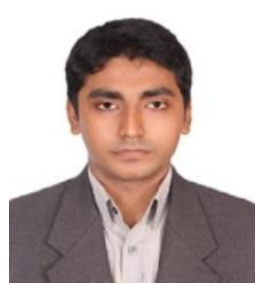

Tareq Mohammad Faruqi received Bachelor of Science (B.Sc.) \& M.Sc in EEE from University of Information Technology \& Sciences (UITS) \& Islamic University of Technology respectively. He started his career in Apri'17 at City University-Bangladesh (CUB) as Lecturer in the Dept. of EEE. His research interest is focused on Machine Learning, VLSI, Digital System Design and Robotics.

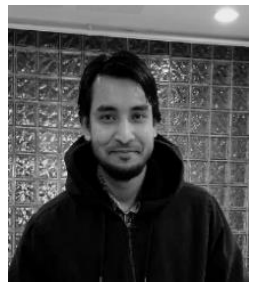

Md Saroar Jahan received his BSc in electrical engineering from the Department of Electrical Engineering \& Electronics, United International University, Bangladesh, in 2013. Received his MSc. degree in Computer Science and Engineering from university Oulu, Finland. He is currently pursuing a Ph.D. degree in Computer Science at the University of Oulu, Finland. His research interests include Big data analysis and deep learning techniques, and Natural Language processing.

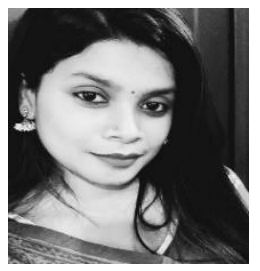

Jhuma Kabir Mim has received her Bachelor of Science degree in CSE from University of Liberal Arts Bangladesh (ULAB). She is currently pursuing her master's degree from LUT University, Finland in Computer Science. Her research interest is focused on Artificial intelligence, IoT, Bioinformatics, and Data analysis. 